\title{
Mutual stabilization of the XcpZ and XcpY components of the secretory apparatus in Pseudomonas aeruginosa
}

\author{
Gérard Michel, Sophie Bleves, Geneviève Ball, Andrée Lazdunski \\ and Alain Filloux
}

Author for correspondence: Gérard Michel. Tel: +33 491164487. Fax: + 33491712124.

e-mail: michel@ibsm.cnrs-mrs.fr

Laboratoire d'Ingénierie des Systèmes Macromoléculaires, UPR9027, IBSM/CNRS, 31 Chemin Joseph Aiguier, 13402 Marseille Cedex 20. France

\begin{abstract}
Protein secretion in Gram-negative bacteria is often dependent on the general secretory pathway (GSP). In Pseudomonas aeruginosa, this system requires at least 12 Xcp (Gsp) proteins, which are proposed to constitute a multiprotein complex localized in the bacterial envelope. Hitherto, little was known about the mutual interactions between Xcp proteins. In this study, mutants affected in the $x c p Z$ gene encoding a bitopic inner-membrane protein were analysed to investigate the role of this protein in the architecture of the secretory machinery. The absence of XcpZ resulted in a decreased amount of XcpY. Reciprocally, XcpZ was not detectable in a XcpY mutant, demonstrating a mutual stabilization of these two proteins. These results strongly suggest that $X c p Z$ and $X c p Y$ interact within the functional secretory apparatus.
\end{abstract}

Keywords: general secretory pathway, protein secretion, protein-protein interaction, protein stability, Pseudomonas aeruginosa

\section{INTRODUCTION}

Translocation of most of the Sec-dependent extracellular proteins across the outer membrane of Gramnegative bacteria occurs via the main terminal branch (MTB) of the general secretory pathway (GSP) (Pugsley, 1993). The MTB of the GSP machineries consists of a set of at least 12 specific proteins (Gsp proteins) and is widely disseminated in the bacterial species so far examined (Tommassen et al., 1992; Lazdunski et al., 1996).

The GSP has been shown to be the major pathway for the secretion of toxins and degradative enzymes in Pseudomonas aeruginosa (Filloux et al., 1990), and in this bacterium the Gsp proteins are named Xcp. The $\mathrm{XcpA}$ protein (referred to as GspO in other Gramnegative bacteria) has been reported to be identical to the peptidase PilD, which catalyses maturation and methylation of the type IV pilins (Nunn \& Lory, 1991; Strom et al., 1993). Five other Gsp proteins, XcpT (GspG), -U (-H), -V (-I), -W (-J) and -X (-K) show homologies to PilA, the structural subunit of the type IV

Abbreviations: GSP, general secretory pathway; MTB, main terminal branch. pilus in $P$. aeruginosa. Since $\mathrm{XcpT}-\mathrm{K}$ also require $\mathrm{XcpA} / \mathrm{PilD}$ for their maturation, they have been referred to as pseudopilins (Bally et al., 1992; Nunn \& Lory, 1993; Bleves et al., 1998). These pseudopilins are presumably present in both membranes, as judged by fractionation studies (Bally et al., 1992; Pugsley \& Possot, 1993). XcpQ (GspD) (Akrim et al., 1993) is the sole protein of the machinery located in the outer membrane, whereas the other Xcp proteins, XcpP (GspC), -R (-E), -S (-F), -Y (-L), -Z (-M) and -A are integrated in, or associated with, the inner membrane (Reeves et al., 1994; Sandkvist et al., 1995; Bleves et al., 1996; Thomas et al., 1997).

Whereas the function of XcpA has clearly been demonstrated, little is known about the functions of the other individual Gsp proteins. Recently, it has been shown that the purified outer-membrane protein XcpQ has a ring-shaped multimeric structure with a central opening, through which the exoproteins probably reach the extracellular medium (Bitter et al., 1998). In some cases, the membrane insertion of GspDs requires the chaperone activity of GspS (Hardie et al., 1996), but GspS homologues have not yet been found in all systems described so far, including the $P$. aeruginosa system.

Except for $g s p O$, the gsp genes of unrelated bacterial species are usually not interchangeable (de Groot et al., 
Table 1. Bacterial strains and plasmids

\begin{tabular}{|c|c|c|}
\hline Strain/plasmid & Relevant characteristics & Reference/source* \\
\hline \multicolumn{3}{|l|}{ Strains } \\
\hline \multicolumn{3}{|l|}{$P$. aeruginosa } \\
\hline PAO1 & Prototroph, $c h l-2$ & B. Holloway ${ }^{1}$ \\
\hline PAO503 & $m e t-9011$ & B. Wretlind ${ }^{2}$ \\
\hline KS902/503 & Isogenic $x c p Z 5$ mutant from PAO503 & Wretlind \& Pavlovskis (1984) \\
\hline KS911/503 & Isogenic $x c p Z 52$ mutant from PAO503 & Wretlind \& Pavlovskis (1984) \\
\hline KS910/503 & Isogenic $x c p Y 51$ mutant from PAO503 & Wretlind \& Pavlovskis (1984) \\
\hline \multicolumn{3}{|l|}{ E. coli } \\
\hline TG1 & supE, hsd $\Delta R$, this $\left(\right.$ lac-proAB) $\mathrm{F}^{\prime}\left(\right.$ traD36 proAB ${ }^{+}$laq $I^{q}$ lacZ $\left.\Delta \mathrm{M} 15\right)$ & \\
\hline \multicolumn{3}{|l|}{ Plasmids } \\
\hline pBluescript & $\mathrm{Ap}^{\mathrm{R}}$ & Stratagene \\
\hline $\mathrm{pMMB} 67 \mathrm{HE} / \mathrm{EH}$ & $\mathrm{Ap}^{\mathrm{R}}$, RSF replicon (IncQ), tac promoter & Fürste et al. (1986) \\
\hline pMMB190 & $\mathrm{Ap}^{\mathrm{R}}, \mathrm{pMMB} 66 \mathrm{EH}$, tac promoter, $\mathrm{LacZ} \alpha$ & Morales et al. (1991) \\
\hline pLAFR3 & Cosmid vector derived from $\mathrm{pLAFR} 1$, IncP1, $\mathrm{Tc}^{\mathrm{R}}$ & Friedman et al. (1982) \\
\hline pUCBM 20 & $A p^{R}$ & Boehringer \\
\hline pYZ4 & $\mathrm{Km}^{\mathrm{R}}$, lacUV $5 \mathrm{p}$ & Zhang \& Broome-Smith (1990) \\
\hline pPHO7 & $\mathrm{Ap}^{\mathrm{R}}$, phoA gene flanked by restriction sites & Gutierrez \& Devedjian (1989) \\
\hline $\mathrm{pHP} 45 \Omega \mathrm{Tc}$ & $\mathrm{Tc}^{\mathrm{R}}, \Omega$ interposon & Fellay et al. (1987) \\
\hline pUEX383 & $\mathrm{Ap}^{\mathrm{R}}, 3.9 \mathrm{~kb}$ EcoRI fragment with $x c p X,-Y$ and $-Z$ in pUC19 & de Groot et al. (1991) \\
\hline pSB22 & $\begin{array}{l}1.8 \mathrm{~kb} E c o \mathrm{RI} / \mathrm{Not} \mathrm{I} \text { fragment of pUEX } 383 \text { carrying the } x c p Z \text { gene in } \\
\text { pUCBM } 20\end{array}$ & This study \\
\hline pSB12 & $\begin{array}{l}1.8 \mathrm{~kb} H i n \mathrm{dIII} / E c o \mathrm{RI} \text { fragment of pSB22 carrying the } x c p Z \text { gene in } \\
\text { pMMB67HE }\end{array}$ & This study \\
\hline pSB51 & 800 bp EcoRI/HindIII fragment encoding ss-'XcpZp in pMMB190 & S. Bleves ${ }^{3}$ \\
\hline pGB1 & $1.8 \mathrm{~kb}$ HindIII/EcoRI fragment of pSB22 (expressing XcpZ) in pYZ4 & This study \\
\hline pGB2 & 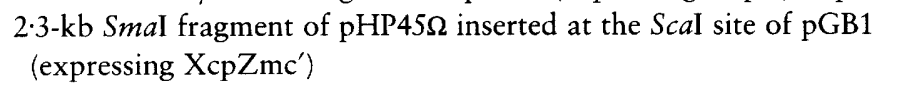 & This study \\
\hline pGB3 & $1 \cdot 2 \mathrm{~kb}$ EcoRV fragment of pGB2 in pMMB190 & This study \\
\hline pGB4 & $1 \cdot 2 \mathrm{~kb} \mathrm{KpnI/EcoRI} \mathrm{fragment} \mathrm{of} \mathrm{pGB3} \mathrm{in} \mathrm{pMMB67HE}$ & This study \\
\hline pGB5 & 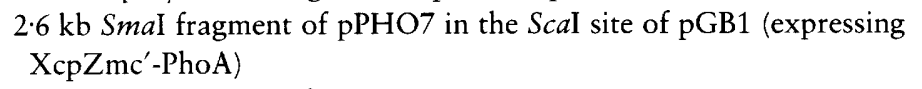 & This study \\
\hline pGB6 & $3 \cdot 2 \mathrm{~kb}$ Sall fragment of pGB5 in pMMB190 & This study \\
\hline pSB31 & $1.4 \mathrm{~kb}$ Sall $/ S p h \mathrm{l}$ fragment carrying the $x c p Y$ gene in pMMB67EH & This study \\
\hline pSB72 & $800 \mathrm{bp}$ EcoRI/HindIII fragment encoding ss-'XcpYp in pMMB190 & S. Bleves \\
\hline pMYS & 700 bp Sall/HindIII fragment encoding XcpYc' in pMMB190 & M. Bally ${ }^{4}$ \\
\hline pMY'-PhoA & $3.4 \mathrm{~kb}$ PstI fragment encoding XcpY $\mathrm{cm}^{\prime}$-PhoA on pMMB67HE & M. Bally \\
\hline pLAFRY & $1.6 \mathrm{~kb}$ EcoRI/HindIII fragment carrying $x c p Y$ in pLAFR3 & M. Bally \\
\hline
\end{tabular}

*1, Monash University, Australia ; 2, Huddinge Hospital, Sweden; 3, Université Catholique de Louvain, Belgium; 4, CNRS Marseille, France.

1991; Pugsley, 1996), suggesting highly specific interactions between the components of the GSP machineries. Yet, in the case of related species (Lindeberg et al., 1996), or for Gsp proteins having a high percentage of identity (Francetic \& Pugsley, 1996), exchangeability can be observed, resulting in the formation of hybrid machineries with variable efficiencies. Cross-linking experiments have pointed out that PulG of Klebsiella oxytoca is able to multimerize in Escherichia coli (Pugsley, 1996). Moreover, the Xcp homologue of PulG, $\mathrm{XcpT}$, has been shown to interact with three other pseudopilins, XcpU, -V and -W (Lu et al., 1997), and with XcpR (Kagami et al., 1998). An alternative way to identify protein-protein interactions is to study the stabilization of one protein by another. For example, Sandkvist et al. (1995) have shown that EpsE of Vibrio cholerae is associated with the cytoplasmic membrane and stabilized via interaction with EpsL, the Gsp homologue of $P$. aeruginosa $\mathrm{XcpY}$. This approach has been extensively used in the case of membrane proteins which belong to complexes such as TonB/ExbB (Skare \& Postle, 1991), SecE/SecY (Nishiyama et al., 1992), the Aeromonas hydrophila GSP components ExeA/ExeB (Howard et al., 1996) or the VirB T-complex transport machinery in Agrobacterium tumefaciens (Fernandez et al., 1996).

Despite some recent advances, specific interactions 
among most of the Xcp proteins have not yet been demonstrated. In this work, using $x c p Z$ mutants, we investigated whether $\mathrm{XcpZ}$ stabilizes other Xcp proteins. Our findings support a model in which $X c p Z$ and $\mathrm{XcpY}$ interact in the functional secretory apparatus in $P$. aeruginosa.

\section{METHODS}

Bacterial strains and plasmids. Bacterial strains and plasmids used in this study are listed in Table 1 . P. aeruginosa strains were grown in tryptone soy broth (Difco) at $37^{\circ} \mathrm{C}$ under agitation and on tryptic soy agar plates containing skim milk (Difco).

DNA manipulations. All plasmid constructions were isolated from E. coli TG1 after transformation. Plasmids were transferred to $P$. aeruginosa by electroporation essentially as described by Smith \& Iglewski (1989). Transformants were isolated on PIA (Pseudomonas isolation agar) plates containing $300 \mu \mathrm{g}$ carbenicillin $\mathrm{ml}^{-1}$ or $200 \mu \mathrm{g}$ tetracycline $\mathrm{ml}^{-1}$. Pseudomonas chromosomal DNA was prepared according to Marmur (1961).

Protein analysis. Cells were harvested at late-exponential phase, and proteins were precipitated with $10 \%$ TCA and washed twice with $90 \%$ acetone. The proteins were then solubilized and separated by SDS-PAGE as described by Laemmli (1970).

Immunoblot analysis. To compare the composition of the cell extracts, the protein contents of equivalent amounts of cells (corresponding to $1 \mathrm{ml}$ culture with an $\mathrm{OD}_{600}$ of $0 \cdot 1$ ) were loaded on polyacrylamide gels. Proteins, separated by SDSPAGE on 10.5 or $15 \%(\mathrm{w} / \mathrm{v})$ polyacrylamide gels, were transferred to nitrocellulose membranes using a semi-dry blot apparatus (Bio-Rad) and incubated with appropriately diluted antisera. Each experiment was performed twice. Either alkaline phosphatase- or peroxidase-conjugated goat antirabbit IgG (Immunotech or Sigma, respectively) were used as secondary antibody. Proteins were revealed by detection of alkaline phosphatase activity or by chemiluminescence (Pierce). The XcpZ rabbit antiserum was raised against a purified recombinant protein obtained by using the pEX fusion system, and XcpY antibodies were raised against a purified glutathione $S$-transferase (GST)-XcpY fusion protein. Semi-quantitative estimation of the relative amounts of proteins detected by chemiluminescence on autoradiography films was carried out by densitometric analysis using a BioRad scanner.

Sequence of the $x c p$ mutant genes and computer analysis. The $x c p$ Y51 allele was amplified by PCR using chromosomal DNA from strain KS910/503 as a template and primers OYG1 (5' AAGAAGGACGAGCGATGAGT $3^{\prime}$ ) and OYG2 (5' TGCGTCATCACCTTCATCTCA 3'). The PCR product was cloned into pUCBM20 and the sequence analysis carried out by ESGS Company (France). The $x c p Z 5$ and $x c p Z 52$ alleles were amplified by PCR using chromosomal DNA templates from strains KS902/503 and KS911/503, respectively, and primers OZG1 (5' GAGAGGATCCCCTGGTGATAGGAGGTT $\left.3^{\prime}\right)$ and OZG2 (5' TATAGAATTCATCGGCCTGTCGCCACACGGT 3'). Direct sequencing on PCR products was carried out by the IBSM sequencing laboratory. Characteristics of predicted mutant proteins were analysed on the Expasy World Wide Web molecular biology server using the ProtParam tool program (Guruprasad et al., 1990).

\section{RESULTS AND DISCUSSION}

\section{The amount of XcpY is decreased in $x c p Z$ mutants}

Little is known about the mutual stabilization of components of the Xcp secretory machinery in $P$. aeruginosa, which we therefore decided to investigate. As a first step, to avoid any polar effect on the expression of other $x c p$ genes, we focused on the influence of mutations in the last gene of the $x c p$ operon, $x c p Z$. The effect associated with the lack of $\mathrm{XcpZ}$ was studied on four other Xcp proteins for which antibodies were available, i.e. XcpQ located in the outer membrane, $\mathrm{XcpR}$ peripherally associated with the inner membrane (M. Bally and others, unpublished), the pseudopilin $\mathrm{XcpT}$ and the bitopic cytoplasmic membrane protein XcpY (Bleves et al., 1996). Two different $x c p Z$ mutants were used in this study, KS902/503 (xcpZ5) and KS911/503 ( $x c p Z 52)$ (Wretlind \& Pavlovkis, 1984). DNA sequencing (see Methods) revealed that the former mutation is a substitution of a thymine for a cytosine (C16T), introducing a stop codon near the $5^{\prime}$ end of the gene. The second mutation is a similar substitution at position 379 in the DNA sequence, generating a stop codon in the DNA encoding the C-terminal periplasmic domain of the protein. In this case, the predicted product should be $5 \cdot 2 \mathrm{kDa}$ smaller than the wild-type protein. However, the mutant $\mathrm{XcpZ}$ protein was not detected in Western blot experiments (data not shown).

Cells from the parent strain PAO503 and the two isogenic $x c p Z$ mutants were grown to late-exponential phase and their proteins were separated by SDS-PAGE. Interestingly, immunoblotting analysis showed that the amount of XcpY was decreased by $25-50 \%$ in the two mutants as compared to the parent strain (Figs 1a, 2b). In contrast, the levels of XcpR (Fig. 1b), XcpQ (data not shown) and XcpT (data not shown) were not affected.
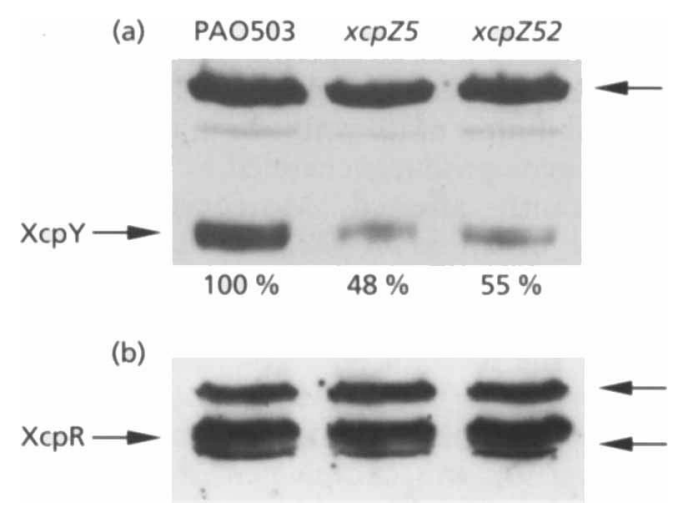

Fig. 1. Amount of $X c p Y$ and $X c p R$ in $x c p Z$ mutants. Cell extracts from $P$. aeruginosa wild-type (PAO503) and isogenic mutants ( $x c p Z 5$ and $x c p Z 52)$ were analysed by Western blotting using anti-XcpY (a) or anti-XcpR (b) antibodies. Immunodetection was carried out by chemiluminescence. Proteins cross-reacting nonspecifically with anti-XcpY and anti-XcpR antibodies are indicated by arrows on the right and were used as quantitative markers. The amount of XcpY protein is expressed as a percentage relative to that of the wild-type strain. 
(a)

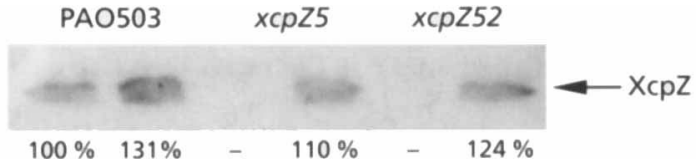

(b)

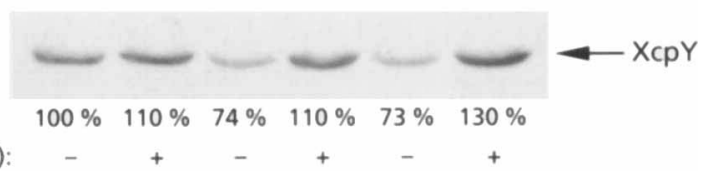

pSB12 (xcpZ):

Fig. 2. Amount of $X c p Y$ in $x c p Z$ mutants complemented by the wild-type $x c p Z$ gene. Plasmid pSB12 carrying the wild-type $x c p Z$ gene or control vector $\mathrm{PMMB67HE}$ were introduced into the wild-type PAO503 and into the $x c p Z 5$ and $x c p Z 52$ mutants. Proteins separated by SDS-PAGE $(10.5 \%$ acrylamide) were analysed by Western blotting using XcpZ (a) and XcpY (b) antibodies. Immunodetection was carried out by chemiluminescence. The amount of XcpY and XcpZ proteins is expressed as a percentage relative to that of the wild-type strain not harbouring pSB12.

Moreover, this decreased level of XcpY appeared not to be due to an increased level of proteases in the periplasm caused by the secretion defect in the $x c p Z$ mutants since it was not significantly affected in other $x c p$ mutants, such as an $x c p Q$ mutant (data not shown). These results suggest that XcpZ stabilizes XcpY.

\section{$x c p Z$ expressed in trans in $x c p Z$ mutants restores XcpY stability}

To check whether the reduced amounts of XcpY in the $x c p Z$ mutants were directly related to the absence of $\mathrm{XcpZ}$, the wild-type $x c p Z$ gene was expressed in trans in the two $x c p Z$ mutants (Fig. 2a). In these strains, the amount of XcpY was restored to the wild-type level (Fig. $2 b)$. This result demonstrates that the amount of XcpY is indeed dependent on the presence of XcpZ. The $x c p Y$ gene is located in a large operon $(x c p R$ to $-Z)$ and it is unlikely that the decreased level of XcpY is due to a feedback inhibition of its synthesis in the $x c p Z$ mutants since other gene products encoded by this operon were not significantly affected. Moreover, we compared the activity of an $x c p R-l a c Z$ transcriptional fusion (Chapon-Hervé et al., 1997) in the $x c p Z$ mutant and in the wild-type strain. No significant difference could be detected at the level of $\beta$-galactosidase activity in all strains tested (data not shown). Concomitant with the stabilization of XcpY, the defect of the $x c p Z$ mutants in elastase secretion was complemented by the introduction of the plasmid harbouring $x c p Z$ (pSB12), showing that the function of the Xcp machinery was restored in both mutants (data not shown).

\section{$\mathrm{XcpY}$ is reciprocally required for the stability of $\mathrm{XcpZ}$}

To further establish a possible interaction between $\mathrm{XcpZ}$ and XcpY, it was relevant to question whether $\mathrm{XcpY}$ could reciprocally stabilize XcpZ. The mutant (a)

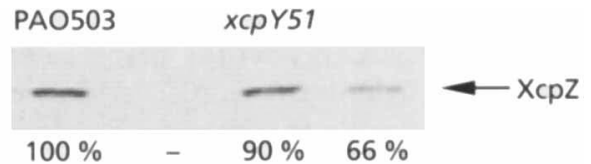

(b)

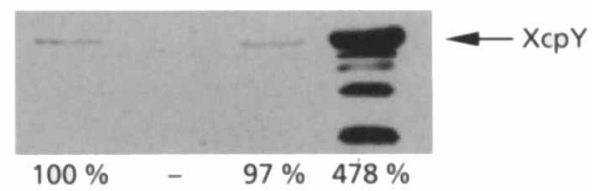

pSB31 (xсpY):

IPTG :

$+\quad+$

Fig. 3. Effect of XcpY on XcpZ stability. Western blot analysis of PAO503 (wild-type) and xcpY51 isogenic mutant cell extracts. Immunodetection was performed by chemiluminescence with anti-XcpZ (a) or anti-XcpY (b) as primary antibodies. The wildtype $x c p Y$ gene carried on pSB31 was introduced into $x c p Y 51$ strain and expression of the gene induced by addition of $2 \mathrm{mM}$ IPTG where indicated. The amount of $X c p Y$ and $X c p Z$ proteins is expressed as a percentage relative to that of the wild-type strain not harbouring pSB31.

KS910/503 (xcpY51) provided an opportunity for studying such a relation. DNA sequencing revealed that this mutation $x c p Y 51$ is an insertion of 7 nucleotides, GCGCAGA, between nucleotide residues 809 and 810 of $x c p Y$ in the region encoding the $\mathrm{C}$-terminal periplasmic domain of the protein. Computing parameters (Guruprasad et al., 1990) predicted an unstable product, $1.25 \mathrm{kDa}$ larger than the wild-type protein and with a basic pI of 11.26 (compared to pI 5.22 for the wild-type protein). No mutant $x c p Y$ gene product was detected after SDS-PAGE and Western blot analysis of extracts from the $x c p Y 51$ mutant (Fig. 3b), possibly because it is unstable and proteolytically degraded. Interestingly, $\mathrm{XcpZ}$ could not be detected in the $x c p Y$ mutant, showing that $\mathrm{XcpY}$ and $\mathrm{XcpZ}$ stabilities are tightly related (Fig. 3a). However, it should be pointed out that in the $x c p Z$ mutants, $\mathrm{XcpY}$ was still present, but in reduced amounts, whilst no $X c p Z$ was detected at all in the $x c p Y$ mutant. These results could be explained by a greater instability of XcpZ in the $x c p Y$ mutant compared to that of XcpY in $x c p Z$ mutants. Since the GspE and GspL homologues of V. cholerae have been shown to interact, $X c p Y$ could partly be stabilized via interaction with $\mathrm{XcpR}$, even if $\mathrm{XcpZ}$ is not present. Introduction of $\mathrm{pSB} 31$ carrying $x c p Y$ in the $x c p Y 51$ mutant resulted in the recovery of a detectable level of XcpZ (Fig. 3a). It should be stressed that the optimal recovery of $\mathrm{XcpZ}$ was obtained when $x c p Y$ was not induced from the tac promoter. In these conditions, the amount of XcpY was similar to that obtained from the chromosomal xcpY copy (Fig. 3b). Upon induction with IPTG, high expression of XcpY resulted in its partial degradation (Fig. 3b) and in a diminished amount of $\mathrm{XcpZ}$, (reduced to $66 \%$ of the control value) (Fig. 3a). Corroborating these data, IPTG induction of $x c p \mathrm{Y}$ expression prevented full complementation of the 
(a)

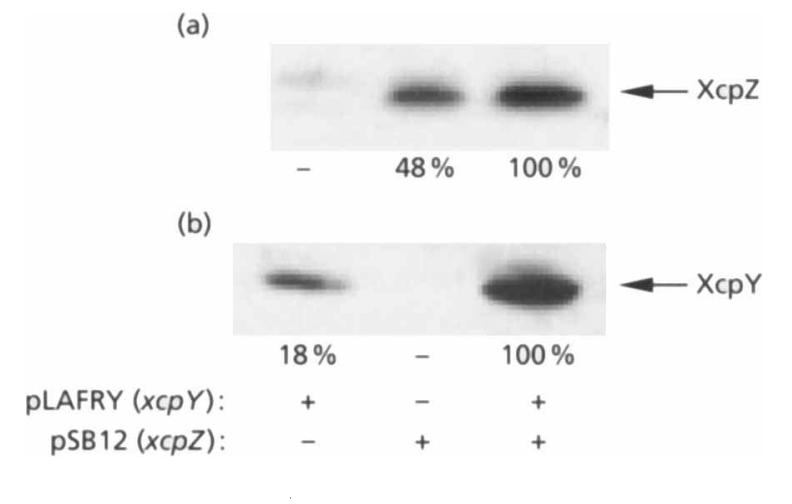

Fig. 4. Amounts of $X c p Y$ and $X c p Z$ produced in $E$. coli. Western blot analysis of TG1 cell extracts containing $x c p Y$ (pLAFRY), $x c p Z$ (pSB12) or both. Immunodetection was performed by chemiluminescence with anti-XcpZ (a) or anti-XcpY (b) as primary antibodies. To prevent production of too large an amount of proteins, gene expression was not induced with IPTG. The amount of XcpY and XcpZ proteins is expressed as a percentage relative to that of the TG1 strain containing both plasmids.

$x c p$ Y 51 mutant as concluded from the size of the haloes around colonies on skim-milk plates, which is a measure of the extracellular proteolytic activity (data not shown). The high production level under these conditions may prevent membrane insertion of XcpY, resulting in aggregation and proteolysis of the protein in the cytosol. Moreover, the results obtained emphasize the fact that the wild-type stoichiometry between the two proteins is important for the assembly of a functional secretory machinery. Whereas the mutual stabilization of XcpZ and XcpY strongly suggests an interaction between these proteins, attempts to directly demonstrate such an interaction were carried out by chemical cross-linking or co-immunoprecipitation using XcpY antibodies. However, in our hands, no physical interaction between these proteins could be detected, suggesting that the interaction between $\mathrm{XcpZ}$ and $\mathrm{XcpY}$ might be a transient event, or that the proteins associate with a low affinity.

\section{Mutual stabilization of XcpY and XcpZ in E. coli}

To demonstrate that the variation in the levels of XcpY and $\mathrm{XcpZ}$ reflects a direct interaction between the two components, the corresponding genes were expressed, individually or together, in E. coli and in the absence of all the other $x c p$ genes. The plasmids carrying $x c p Y$ (pLAFRY) and $x c p Z$ (pSB12) were transformed or cotransformed in E. coli TG1. Cell extracts from the different strains were then analysed by SDS-PAGE and Western blotting for the presence of the XcpY and XcpZ proteins. It appears that the coexpression resulted in an increased level of each protein as compared to the level obtained when each gene was expressed individually (Fig. 4). This result is strongly in favour of a direct interaction between $\mathrm{XcpY}$ and $\mathrm{XcpZ}$, resulting in an increased stability of these proteins within the complex they form. (a)

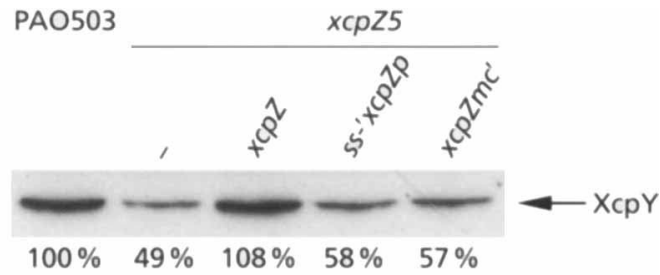

(b)

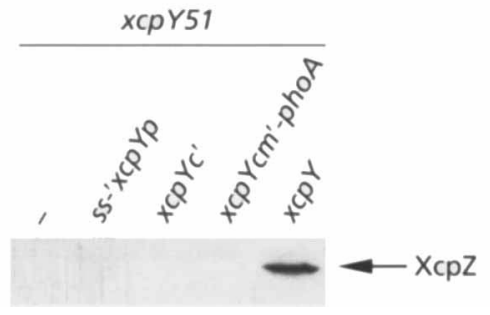

Fig. 5. (a) Amount of $X c p Y$ in the presence of various domains of $X c p Z$. The periplasmic domain of XcpZ was expressed as a truncated protein (ss-'XcpZp) from pSB51, whilst the membrane and cytoplasmic domains of $\mathrm{XcpZ}$ (XcpZmc') were expressed as a truncated protein from pGB4 in the $P$. aeruginosa $x c p Z 5$ mutant. XcpY was analysed by Western blotting and the protein immunodetected by chemiluminescence. The amount of $X \mathrm{cpY}$ is expressed as a percentage relative to that of the wild-type strain. (b) Influence of various domains of XcpY on the amount of $X \mathrm{cpZ}$. Plasmids carrying genes encoding ss'XcpYp (pSB72), XcpYc' (pMYS), XcpYcm'-PhoA (pMY'-PhoA) and $X c p Y$ (pSB31) were introduced into the $x c p Y 51$ mutant strain. Expression of $x c p Y$ and derivatives was induced with $2 \mathrm{mM}$ IPTG. Cell extracts were analysed by Western blotting and immunodetection was performed by chemiluminescence using anti-XcpZ antisera.

\section{Separate protein domains of $\mathrm{XcpZ}$ or $\mathrm{XcpY}$ are not

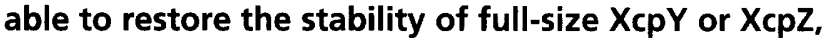 respectively}

To investigate whether XcpY could be stabilized by the periplasmic domain of XcpZ alone, plasmid pSB51 encoding a mutant $\mathrm{XcpZ}$ protein (ss-' $\mathrm{XcpZp}$ ), in which the cytoplasmic domain and the membrane anchor of $\mathrm{XcpZ}$ are replaced by the signal peptide of the $P$. aeruginosa elastase (LasB), was introduced in the $x c p Z 5$ mutant strain. The truncated 'XcpZp protein could clearly be detected by immunoblotting (data not shown). However, expression of the periplasmic domain of XcpZ ('XcpZp) did not stabilize XcpY (Fig. 5a). The influence of membrane and cytoplasmic domains of $\mathrm{XcpZ}$ was also investigated. For this purpose, two constructs were engineered. The product of one construct, generated by the insertion of a stop codon in $x c p Z$ (pGB4), could not be detected (data not shown) and did not stabilize XcpY (Fig. 5a). The other construct, pGB6 encoding a $x c p Z^{\prime}$ $-p h o A$ gene fusion, resulted in the synthesis of a protein of the expected size $(54.6 \mathrm{kDa})$ which was revealed on immunoblots with antiserum directed against PhoA. As for pGB4, the presence of pGB6 did not stabilize XcpY (data not shown).

The influence of the $\mathrm{XcpY}$ domains on $\mathrm{XcpZ}$ was 


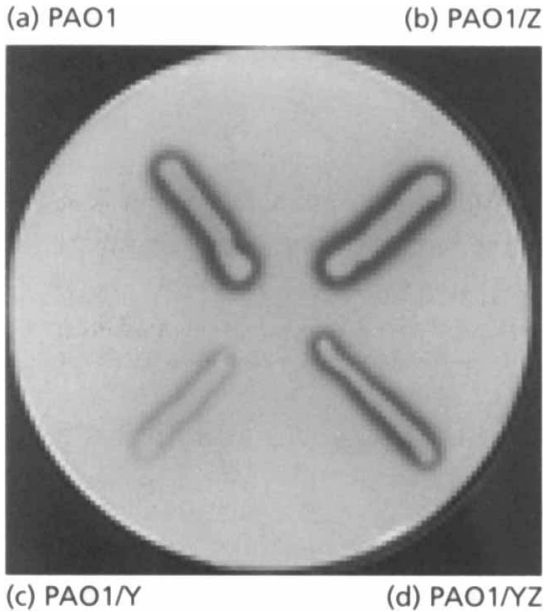

Fig. 6. Effect of overexpression of $X c p Z$ on the negative dominant effect caused by XcpY overproduction. Proteolytic activity was analysed on a skim-milk plate with $P$. aeruginosa containing the vectors PMMB67HE and pLAFR3 (a), plasmids expressing either $x c p Z$ (pSB12) (b) or $x c p Y$ (pLAFRY) (c) or both simultaneously (d). The plate contained $500 \mu \mathrm{g}$ carbenicillin $\mathrm{ml}^{-1}, 200 \mu \mathrm{g}$ tetracycline $\mathrm{ml}^{-1}$ and $2 \mathrm{mM}$ IPTG.

similarly studied. Three constructs were used, one encoding the $\mathrm{C}$-terminal periplasmic domain of $\mathrm{XcpY}$ fused to the LasB signal peptide (ss-'XcpYp encoded on pSB72), one encoding the N-terminal cytoplasmic domain of XcpY (XcpYc' encoded on pMYS), and one encoding the $\mathrm{N}$-terminal domain including the transmembrane segment fused to PhoA (XcpYcm'-PhoA encoded on $\mathrm{pMY}$ '-PhoA). Even though each of the proteins could be visualized by immunoblotting (data not shown), neither of them was sufficient to restore the wild-type level of XcpZ (Fig. Sb).

Thus, in this way, we could not identify a particular domain of either XcpZ or XcpY that is responsible for the stabilizing effect. Rather, these results suggest that expression of the truncated forms could result in misfolded protein domains, which cannot properly interact, and therefore that the entire proteins might be necessary to promote a mutual stabilizing effect.

\section{Interference associated with $\mathrm{XcpY}$ overexpression is relieved upon co-overexpression of $\mathrm{XcpZ}$}

As already mentioned, the stoichiometry of the Xcp components appears to be an important parameter for the proper functioning of the secretory machinery. Overexpression of XcpY from plasmid pLAFRY in the wild-type $P$. aeruginosa strain PAO1 had a dominant negative effect on protein secretion, referred to as interference, as revealed by the reduced proteolytic activity on skim-milk plates (Fig. 6). Since the data presented above suggest an interaction between XcpZ and XcpY, the interference due to XcpY overexpression could possibly be alleviated by co-overexpression of
XcpZ. Indeed PAO1 cells containing pSB12 $(x c p Z)$ in addition to pLAFRY $(x c p Y)$ developed wild-type haloes on skim-milk plates (Fig. 6). Immunoblotting revealed that the level of XcpY produced in both cases was similar, indicating that the suppression of interference was due to $\mathrm{XcpZ}$ overexpression (data not shown).

Sandkvist et al. (1995) have shown that EpsE and EpsL from $V$. cholerae interact with each other, and it appears that XcpR and XcpY behave similarly within the Xcp system (M. Bally and others, unpublished). The interference phenomenon observed when XcpY is overproduced could be explained by the titration of XcpR with an excess of XcpY in areas of the membrane lacking an additional partner essential for the assembly of a functional Xcp machinery. On the basis of the data presented here, one could speculate that $\mathrm{XcpZ}$ is this additional partner. $X c p Z$ would dock $X c p Y$ or the $\mathrm{XcpY} / \mathrm{XcpR}$ complex to an appropriate membrane site for further assembly of the secretory machinery.

In conclusion, the data presented here argue in favour of a specific interaction between two proteins of a GSP secretory system, XcpZ and XcpY, which is an important addition to our understanding of the architecture of this machinery. The method used to show the interdependence between both proteins is very useful and will be further exploited when non-polar mutants in all $x c p$ genes and antisera against all $\mathrm{Xcp}$ proteins become available.

\section{ACKNOWLEDGEMENTS}

The authors would like to thank Marc Bally for sharing unpublished data, and for giving plasmids pMYS and pLAFRY, and XcpZ and XcpR antisera; Wilbert Bitter for providing XcpQ antisera; Paul Sauve for oligonucleotide synthesis; Olivier Uderso for preparation of all media and buffers; and Jeanine Busutil for DNA sequencing. Sophie Bleves is supported by the Ministry of Research and Technology and the whole work was partly supported by the French cystic fibrosis foundation, AFLM (Association Française de Lutte contre la Mucoviscidose) and by the Biotech Framework IV grant number BI04 CT960119 from the European Union to Cell Factories Network.

\section{REFERENCES}

Akrim, M., Bally, M., Ball, G., Tommassen, J., Teerink, H., Filloux A. \& Lazdunski, A. (1993). Xcp-mediated protein secretion in Pseudomonas aeruginosa: identification of two additional genes and evidence for regulation of $x c p$ gene expression. Mol Microbiol 10, 431-443.

Bally, M., Filloux, A., Akrim, M., Ball, G., Lazdunski, A. \& Tommassen, J. (1992). Protein secretion in Pseudomonas aeruginosa: characterization of seven $x c p$ genes and processing of secretory apparatus components by prepilin peptidase. $\mathrm{Mol}$ Microbiol 6, 1121-1131.

Bitter, W., Koster, M., Latijnhouwers, M., de Cock, H. \& Tommassen, J. (1998). Formation of oligomeric rings by XcpQ and PilQ, which are involved in protein transport across the outer membrane of Pseudomonas aeruginosa. Mol Microbiol 27, 209-219. 
Bleves, S., Lazdunski, A. \& Filloux, A. (1996). Membrane topology of three Xcp proteins involved in exoprotein transport by Pseudomonas aeruginosa. J Bacteriol 178, 4297-4300.

Bleves, S., Voulhoux, R., Michel, G., Lazdunski, A., Tommassen, J. \& Filloux, A. (1998). The secretion apparatus of Pseudomonas aeruginosa: identification of a fifth pseudopilin, XcpX (GspK family). Mol Microbiol 27, 159-170.

Chapon-Hervé, V., Akrim, M., Latifi, A., Williams, P., Lazdunski, A. \& Bally, M. (1997). Regulation of the $x c p$ secretion pathway by multiple quorum-sensing modulons in Pseudomonas aeruginosa. Mol Microbiol 24, 1169-1178.

Fellay, R., Frey, J. \& Krisch, H. (1987). Interposon mutagenesis of soil and water bacteria : a family of DNA fragments designed for in vitro insertional mutagenesis of gram-negative bacteria. Gene 52, 147-154.

Fernandez, D., Spudich, G. M., Zhou, X.-R. \& Christie, P. J. (1996). The Agrobacterium tumefaciens VirB7 lipoprotein is required for stabilization of VirB proteins during assembly of the T-complex transport apparatus. J Bacteriol 178, 3168-3176.

Filloux, A., Bally, M., Ball, G., Akrim, M., Tommassen, J. \& Lazdunski, A. (1990). Protein secretion in gram-negative bacteria: transport across the outer membrane involves common mechanisms in different bacteria. EMBO J 9, 4323-4329.

Francetic, O. \& Pugsley, A. P. (1996). The cryptic general secretory pathway ( $g s p$ ) operon of Escherichia coli K-12 encodes functional proteins. J Bacteriol 178, 3544-3549.

Friedman, A. M., Long, S. R., Brown, S. E., Buikema, W. J. \& Ausubel, F. M. (1982). Construction of a broad host range cosmid cloning vector and its use in the genetic analysis of Rhizobium mutants. Gene 18, 289-296.

Fürste, J. P., Pansegrau, W., Frank, R., Blöcker, H., Scholz, P., Bagdasarian, M. \& Lanka, E. (1986). Molecular cloning of the plasmid RP4 primase region in a multi-host-range tacP expression vector. Gene 48, 119-131.

de Groot, A., Filloux, A. \& Tommassen, J. (1991). Conservation of $x c p$ genes, involved in the two-step secretion process, in different Pseudomonas species and other Gram-negative bacteria. Mol Gen Genet 229, 278-284.

Guruprasad, K., Reddy, B. V. \& Pandit, M. W. (1990). Correlation between stability of a protein and its dipeptide composition: a novel approach for predicting in vivo stability of a protein from its primary sequence. Protein Eng 4, 155-161.

Gutierrez, C. \& Devedjian, J. C. (1989). A plasmid facilitating in vitro construction of phoA gene fusions in Escherichia coli. Nucleic Acids Res 17, 3999.

Hardie, K. R., Lory, S. \& Pugsley, A. P. (1996). Insertion of an outer membrane protein in Escherichia coli requires a chaperone-like protein. EMBO J 15, 978-988.

Howard, S. P., Meiklejohn, H. G., Shivak, D. \& Jahagirdar, R. (1996). A TonB-like protein and a novel membrane protein containing an ATP-binding cassette function together in exotoxin secretion. Mol Microbiol 22, 595-604.

Kagami, Y., Ratliff, M., Surber, M., Martinez, A. \& Nunn, D. N. (1998). Type II protein secretion by Pseudomonas aeruginosa: genetic suppression of a conditional mutation in the pilin-like component XcpT by the cytoplasmic component XcpR. Mol Microbiol 27, 221-233.

Laemmli, U. K. (1970). Cleavage of structural proteins during the assembly of the head of bacteriophage T4. Nature 227, 680-685.

Lazdunski, A., Filloux, A., Michel, G., Foglino, M., Murgier, M., Latifi, A., Chapon, V., Bleves, S. \& Bally, M. (1996). The general secretion pathway in Pseudomonas aeruginosa: molecular mechanisms and regulation. In Proceedings of the Fifth International Symposium on Pseudomonads: Molecular Biology and Biotechnology, pp. 427-437. Edited by T. Nakazawa, K. Furukawa, D. Haas \& S. Silver. Washington, DC: American Society for Microbiology.

Lindeberg, M., Salmond, G.P. C. \& Collmer, A. (1996). Complementation of deletion mutations in a cloned functional cluster of Erwinia chrysanthemi out genes with Erwinia carotovora out homologues reveals OutC and OutD as candidate gatekeepers of species-specific secretion of proteins via the type II pathway. Mol Microbiol 20, 175-190.

Lu, H.-M., Motley, S. T. \& Lory, S. (1997). Interactions of the components of the general secretion pathway: role of Pseudomonas aeruginosa type IV pilin subunits in complex formation and extracellular protein secretion. Mol Microbiol 25, 247-259.

Marmur, J. (1961). A procedure for the isolation of deoxyribonucleic acid from micro-organisms. $J$ Mol Biol 3, 208-218.

Morales, V. M., Bäckman, A. \& Bagdasarian, M. (1991). A series of wide-host-range low-copy-number vectors that allow direct screening for recombinants. Gene 97, 39-47.

Nishiyama, K., Mizushima, S. \& Tokuda, H. (1992). The carboxylterminal region of SecE interacts with SecY and is functional in the reconstitution of protein translocation activity in Escherichia coli. J Biol Chem 267, 7170-7176.

Nunn, D. N. \& Lory, S. (1991). Product of the Pseudomonas aeruginosa gene pilD is a prepilin leader peptidase. Proc Natl Acad Sci USA 88, 3281-3285.

Nunn, D. N. \& Lory, S. (1993). Cleavage, methylation, and localization of the Pseudomonas aeruginosa export proteins XcpT, -U, -V, and -W. J Bacteriol 175, 4375-4382.

Pugsley, A. P. (1993). The complete general secretion pathway in Gram-negative bacteria. Microbiol Rev 57, 50-108.

Pugsley, A. P. (1996). Multimers of the precursor of a type IV pilin-like component of the general secretory pathway are unrelated to pili. Mol Microbiol 20, 1235-1245.

Pugsley, A. P. \& Possot, O. (1993). The general secretory pathway of Klebsiella oxytoca: no evidence for relocalization or assembly of pilin-like PulG protein into a multiprotein complex. Mol Microbiol 10, 665-674.

Reeves, P. J., Douglas, P. \& Salmond, P. C. (1994). Beta-lactamase topology probe analysis of the OutO NMePhe peptidase, and six other Out protein components of the Erwinia carotovora general secretion pathway apparatus. Mol Microbiol 12, 445-457.

Sandkvist, M., Bagdasarian, M., Howard, S. P. \& DiRita, V. J. (1995). Interaction between the autokinase EpsE and EpsL in the cytoplasmic membrane is required for extracellular secretion in Vibrio cholerae. EMBO J 14, 1664-1673.

Skare, J. T. \& Postle, K. (1991). Evidence for a TonB-dependent energy transduction complex in Escherichia coli. Mol Microbiol 5, 2883-2890.

Smith, A. W. \& Iglewski, B. H. (1989). Transformation of Pseudomonas aeruginosa by electroporation. Nucleic Acids Res 17, 10509.

Strom, M. S., Nunn, D. N. \& Lory, S. (1993). A single bifunctional enzyme, PilD, catalyzes cleavage and $\mathrm{N}$-methylation of proteins belonging to the type IV pilin family. Proc Natl Acad Sci USA 90, 2404-2408.

Thomas, J. D., Reeves, P. J. \& Salmond, G. P. C. (1997). The general secretion pathway of Erwinia carotovora subsp. carotovora: analysis of the membrane topology of OutC and OutF. Microbiology 143, 713-720.

Tommassen, J., Filloux, A., Bally, M., Murgier, M. \& Lazdunski, A. 
(1992). Protein secretion in Pseudomonas aeruginosa. FEMS Microbiol Rev 103, 73-90.

Wretlind, B. \& Pavlovskis, O. R. (1984). Genetic mapping and characterization of Pseudomonas aeruginosa mutants defective in the formation of extracellular proteins. J Bacteriol 158, 801-808.

Zhang, Y. B. \& Broome-Smith, J. K. (1990). Correct insertion of a simple eukaryotic plasma-membrane protein into the cytoplasmic membrane of Escherichia coli. Gene 96, 51-57.

Received 19 March 1998; revised 30 July 1998; accepted 7 September 1998. 